\title{
Comparative study of protein pattern changes and mineral composition in cultivated and newly domesticated wild Flammulina velutipes
}

\author{
Hashemian SM${ }^{1}$, Pourianfar $\mathrm{HR}^{2 *}$, Rezaeian S-H ${ }^{2 *}$ \\ ${ }^{1}$ Department of Chemistry, Ferdowsi University of Mashhad, Mashhad, Iran \\ ${ }^{2}$ Industrial Fungi Biotechnology Research Department, Research Institute for Industrial Biotechnology, Academic \\ Center for Education, Culture and Research (ACECR), Khorasan Razavi Province Branch, P.O.Box: 91775-1376, \\ Mashhad-Iran
}

Hashemian SM, Pourianfar HR, Rezaeian S-H 2019 - Comparative study of protein changes and mineral composition in cultivated and newly domesticated wild Flammulina velutipes. Studies in Fungi 4(1), 282-291, Doi 10.5943/sif/4/1/30

\begin{abstract}
A wild strain of Flammulina velutipes indigenous to Iran has been recently adapted for artificial cultivation, requiring nutritional information in order to improve its utilization as a medicinal-culinary mushroom. Thus, the current study aimed to evaluate protein profile of this domesticated wild $F$. velutipes strain over six different developmental stages, in comparison with a commercially cultivated strain of F. velutipes. Various macro- and microelements were also investigated in the mature sporomes cultivated in a lignocellulosic substrate composed of $40 \%$ wheat straw $+40 \%$ sawdust $+18 \%$ wheat bran $+1 \%$ lime $+1 \%$ gypsum. The lowest and highest amounts of protein were observed in primordia (33\% of dry matter) and sporomes picked at the third or fifth day of harvesting ( $57 \%$ of dry matter), respectively $(p \leq 0.05)$, followed by an obvious decrease in protein content at the late stages of harvesting $(p \leq 0.05)$. Further SDS-PAGE analyses revealed that the protein molecular mass increased from less than $30 \mathrm{kDa}$ in primordia to $235 \mathrm{kDa}$ in mature sporomes. However, no significant difference in protein profiling was noticed between the wild and the reference strains of any given stage $(p \geq 0.05)$. While nutritional elements such as $\mathrm{K}, \mathrm{P}$ and $\mathrm{Mg}$ were found at 886.9, 745.2, and $142.7 \mathrm{mg} / 100 \mathrm{~g}$ of dry weight, respectively, no heavy metals was found at levels higher than the provisional maximum tolerable intake in the sporomes. This study may be considered an initial step towards recognition of the wild $F$. velutipes as a nontoxic functional food, warranting further proteomics studies.
\end{abstract}

Key words - Developmental stages - Nutritional elements - PAGE - Protein content - SDS Wild mushrooms

\section{Introduction}

Continuous in-depth evaluation of nutritional values of cultivated medicinal mushrooms has demonstrated that they are one of the most prominent sources of nutraceuticals. Some of the most recently published researches on well-known cultivated medicinal mushrooms include Lentinula edodes (Berk.) Pegler (Li et al. 2018), Flammulina velutipes (Curtis) Singer (Tsai et al. 2017), and Pleurotus ostreatus (Jacq.) P. Kumm. (Tolera \& Abera 2017). However, these types of studies do 
not necessarily reflect the nutritional potentiality of all the wild-growing mushroom species. Of approximately 14,000 taxonomically recognized mushroom species, about 200 are experimentally grown, 100 economically cultivated, around 60 commercially cultivated, and more than 10 have reached industrial scale in commercial cultivation in many countries (Wasser 2014, Miles \& Chang 2004). Moreover, the commercially cultivated species may have numerous wild counterparts growing in different habitats, remaining a huge genetic diversity among wild mushrooms to be explored.

In addition to mushroom cultivars, a growing number of researches have been also done on nutritional properties and composition of wild mushrooms, focusing on medicinal mushrooms directly collected from the wild (Quarcoo et al. 2014, Sharma \& Atri 2014, Mridu \& Atri 2017, Sharif et al. 2017). By contrast, very limited studies have evaluated nutritional composition and medicinal properties of sporomes of wild mushrooms domesticated in artificial substrates, for example Ganoderma neo-japonicum Imazeki (Tan et al. 2015), the HS isolate of wild Pleurotus spp. (Sulistiany et al. 2016), and Ganoderma australe (Fr.) Pat. (Luangharn et al. 2017). Domestication of wild mushrooms in locally available lignocellulosic substrates may provide benefits for conservation of rare wild species as well as regional economy for mushroom growers. In addition, it provides an alternative way to overcome the limited supply of wild mushrooms (Tan et al. 2015). The continuous mushroom production in high amounts and in a standardized quality is also important to facilitate reproducibility of biomedical or nutraceutical research on wild mushrooms (Lindequist et al. 2005).

Culinary-medicinal mushroom Enoki, F. velutipes, ranks fifth among cultivated mushrooms in the world (Royse et al. 2017), comprising of commercially cultivated strains and wild types. Recently, we reported the successful domestication and evaluated agronomic characterization of an Iranian wild Enoki strain (in comparison with a commercial strain) on various locally available agro-wastes (Rezaeian \& Pourianfar 2017). Following domestication of wild mushrooms, assessment of nutritional/toxic minerals and protein content in sporomes of edible newly cultivated wild mushrooms should be investigated, as it directly associates with human food safety and protein nutrition or malnutrition particularly in developing countries (Jaworska et al. 2014, Kalač 2009, Sharma \& Gautam 2015). Besides, proteins present in sporomes of wild mushrooms have a variety of important biological activities (Lau et al. 2012). Thus, the current study sought to address protein content, protein profiling over different developmental stages, and the presence of macro and micro dietary elements in Iranian native newly domesticated $F$. velutipes in comparison with a reference commercial strain.

\section{Materials \& Methods}

\section{Chemicals \& reagents}

The following reagents (analytical grade) including acetic acid (AC), methanol (MeOH), Tris (hydroxymethyl) aminomethane, glycine, N, N-methyl-enebisacrylamide (Bis), acrylamide, sodium dodecyl sulfate (SDS), ammonium persulfate (APS), sodium carbonate, mercaptoethanol, formaldehyde, tetramethylethylenediamine (TEMED), bovine serum albumin (BSA), and sodium thiosulfate were all purchased from Merck (Darmstadt, Germany). Standard protein ladders and phenylmethane sulfonyl fluoride (PMSF) were prepared from Cinnagen Co. (Iran) and Sigma, respectively. Malt extract agar from Merck (Darmstadt, Germany) was also used as solid media for growing and maintenance of mycelial cultures of the tested Enoki mushrooms. In all the experimental steps, deionized water was utilized to prepare solutions and buffers.

\section{Production of fresh Enoki sporomes}

The wild-growing strain of $F$. velutipes mushroom utilized in this study has been previously collected and identified by our group (Rezaeian \& Pourianfar 2017). In addition, a commercially cultivated strain of F. velutipes (M4622-mcup-2) purchased from Mycelia (Belgium) was used as the reference. Based on the findings of the previous study (Rezaeian \& Pourianfar 2017), the 
following substrate was selected for production of fresh sporomes: $40 \%$ wheat straw $+40 \%$ sawdust $+18 \%$ wheat bran $+1 \%$ lime $+1 \%$ gypsum. Mycelial culture, spawn preparation, and mushroom fructification were carried out by procedures previously described (Rezaeian \& Pourianfar 2017) with modifications. The fresh sporomes were sampled related to six developmental stages including, primordia and mature sporomes harvested at three, five, seven, nine and eleven days after appearance of primordia. Harvested mushrooms in each developmental stage were immediately stored at $-80^{\circ} \mathrm{C}$ in order to prevent protein disintegration before use. The harvested sporomes were further dried using lyophilization (Buchi B-191, Switzerland).

\section{Total protein extraction}

Total protein was extracted from the lyophilized powder of each sporome harvested at various developmental stages, based on a modified method reported elsewhere (Liu et al. 2012). In brief, $1 \mathrm{X}$ phosphate buffered saline (PBS) was manually made at a $\mathrm{pH}$ of 7.4. In order to neutralize protease enzymes, 1\% PMSF (v/v) was added to the PBS solution. Then, $40 \mathrm{mg}$ of the mushroom powder was re-suspended in one $\mathrm{mL}$ of PBS containing PMSF followed by grinding technique using liquid nitrogen for five minutes. After centrifugation $\left(2880 \times \mathrm{g}, 2 \mathrm{~min}, 4^{\circ} \mathrm{C}\right)$, the supernatant was collected to serve as soluble crude proteins.

\section{Protein measurements}

The total protein content was determined using the Bradford method (Bradford 1976) based on the reaction of extracted proteins with Coomassie Brilliant Blue. Five $\mathrm{mL}$ of Bradford Reagent $(1 \mathrm{x}, 0.1 \mathrm{mg} / \mathrm{mL}$ in $\mathrm{MeOH}$ ) was added into $100 \mu \mathrm{L}$ of BSA (at various concentrations) followed by incubation at $4^{\circ} \mathrm{C}$ for $20 \mathrm{~min}$. The absorbance was then measured at $595 \mathrm{~nm}$ with a UV/VIS spectrophotometer (Epoch 2 Microplate Spectrophotometer from BioTek). Absorbance values for BSA generated a standard curve in the range of $200-1000 \mu \mathrm{g} / \mathrm{mL}$ with the following equation: $\mathrm{Y}=$ $0.2728 \mathrm{X}+0.423\left(\mathrm{R}^{2}=0.9822\right)$. The same procedure was carried out with the soluble crude proteins extracted from Enoki mushrooms. Total protein content was then extrapolated using the curve equation and expressed as percentage of mushroom dry weight.

\section{Protein analysis}

Sodium Dodecyl Sulfate-Polyacrylamide Gel Electrophoresis (SDS-PAGE) was used to obtain the primary profile of total protein extracts obtained from each developmental stage using a vertical slab gel apparatus. Sample buffer and crude proteins were mixed at a ratio of $1: 1(\mathrm{v} / \mathrm{v})$ and boiled for $5 \mathrm{~min}$ at $96^{\circ} \mathrm{C}$. Seven $\mathrm{mL}$ of a mixture of broad range protein ladder was loaded into the wells. Electrophoresis was conducted at a constant current of $110 \mathrm{~V}$ to move the proteins through both the stacking and resolving gel (4\% and $12 \%$ polyacrylamide, respectively). Following electrophoresis, the gel was fixed with a solution consisting of $40 \%(\mathrm{v} / \mathrm{v}) \mathrm{MeOH}$ and $10 \%(\mathrm{v} / \mathrm{v})$ AC for 20 minutes. The protein bands were then stained by Coomassie brilliant blue for three hours.

\section{Macro- and microelement content in sporomes}

Nutritional and toxic elements present in the tested sporomes of $F$. velutipes were determined using an ICP-UV/VIS instrument (Spectra ARCOS, Germany, Model number 76004555). The limit of detection was determined and the quantitative analyses were carried out under the instrumental condition for all studied elements (Table 1).

\section{Statistical analysis}

Each experiment was independently repeated at least three times. Graph prism version 5 was utilized to conduct statistical analyses and ANOVA tests. Means were compared using Tukey method with a significance level ( $p$ value) of 0.05 . For protein analysis, the background was normalized with advanced imageJ software using rolling ball algorithm (optimum radius, 50) and protein signals were detected by GelAnalyzer software followed by PlotDigitizer (Zarei et al. 2015). 
Table 1 Instrumental conditions of ICP-UV/VIS for all studied elements.

\begin{tabular}{ll}
\hline Instrument name & Type \\
\hline Nebulizer & Cross flow \\
Rf power & $1400 \mathrm{w}$ \\
Nebulizer gas (argon) flow rate & $1 \mathrm{~L} / \mathrm{min}$ \\
Introduction of the sample & $1.5 \mathrm{~mL} / \mathrm{min}$ \\
Pump speed & 30 rotations per minute \\
Number of replicates & 1 \\
\hline
\end{tabular}

\section{Results}

\section{Determination of total protein content}

To overcome the inaccuracies borne in mushroom moisture contents, total protein measurements were determined as a percentage of dry matter. As illustrated in Fig. 1, total protein content of $F$. velutipes harvested in different maturation stages displayed an age-dependent bellshaped curve. The lowest amount of protein (33\%) was observed in primordia as the initial step of fructification. Following stipe elongation and cap expansion, the highest protein content (57\%) was measured in sporomes harvested at the third and fifth days of harvesting $(p \leq 0.05)$, as compared to other stages of fructification. Then, an obvious decrease in protein content was seen in mature mushrooms (at the ninth day of harvesting) $(p \leq 0.05)$. However, no significant difference in protein content was noticed between the wild and the reference strains of $F$. velutipes at any given stage $(p \geq 0.05)$.

\section{Protein profiling}

Total crude proteins of the wild F. velutipes were analyzed by SDS-PAGE in order to compare changes in protein patterns obtained from six developmental stages, using $12 \%$ acrylamide gel. Both clear distinct bands and unclear bands were observed in the protein banding patterns, with molecular masses ranged from $9 \mathrm{kDa}$ to $235 \mathrm{kDa}$. The number of protein bands increased over mushroom maturation from 12 clear distinct protein bands at the primordial stage to 21 bands in the $11^{\text {th }}$ day of harvesting. The SDS-PAGE analysis also showed variations in the molecular size of protein bands observed over the different stages of harvesting $(p \leq 0.05)$. According to Fig. 2, the primordial phase showed mostly proteins of low molecular mass $(<30$ $\mathrm{kDa}$ ), whilst mushrooms harvested at the late phases showed higher molecular mass proteins.

\section{Elemental profile}

Various elements were observed in both wild and the reference strains, including essential elements and some heavy metals. However, there was no significant difference in the presence or the quantity of elements between the wild and reference strain $(p \geq 0.05)$. As shown in Fig. $3, \mathrm{~K}$ was estimated to be 876.7 and $886.9 \mathrm{mg} / 100 \mathrm{~g}$ of dry weight for the reference and wild strain, respectively. In the wild strain, $\mathrm{P}$ was also recorded at a high content $(745.2 \mathrm{mg} / 100 \mathrm{~g}$ of dry weight) followed by $\mathrm{Mg}$ (142.7 mg/100g of dry weight) none of which showed significant difference from those of the reference strain. $\mathrm{Fe}, \mathrm{Ca}, \mathrm{Na}$ and $\mathrm{Zn}$ were also present in concentrations of 8.102, 29.23, 37.24 and $6.961 \mathrm{mg} / 100 \mathrm{~g}$, respectively. In addition, trace amounts $(2-6 \mathrm{mg} / 100 \mathrm{~g}$ of dry weight) of $\mathrm{Cr}, \mathrm{Pb}, \mathrm{Cu}$, and $\mathrm{Mn}$ were also found, while concentrations of $\mathrm{Ni}, \mathrm{Cd}$, and Ar were less than $0.08 \mathrm{mg} / 100 \mathrm{~g}$ of dry weight. Co, Li and Ag were below detection levels.

\section{Discussion}

The current study for the first time showed that the protein content of a newly domesticated wild Enoki mushroom is similar to that of the commercially cultivated Enoki mushroom in all the stages of sporome development. The findings of this study also showed that the highest protein content ( $57 \%$ per dry matter) is present in sporomes harvested at the third and fifth days after 
appearance of primordia. At the present, data on changes in protein contents of edible wild-growing mushrooms over different stages of sporomes (i.e. primordium, immature or mature sporome) is limited to some edible wild mushrooms, despite the global trend in growing and domestication of various wild mushroom species (Herawati et al. 2016, Salmones et al. 2018, Shahtahmasebi et al. 2018, Arana-Gabriel et al. 2018, Debnath et al. 2019). A few proteomic studies have addressed changes in protein expression at molecular level (related to mushroom development or specific proteins such as lectin) during different developmental stages of wild or cultivated edible mushrooms (Chen et al. 2012, Nikitina et al. 2017, Rahmad et al. 2014). It should be noted that protein contents of mushrooms not only are dependent on developmental processes but also are affected by mushroom species/strain, environmental conditions, and even formulation and structure of the substrate (Hoa et al. 2015, Li et al. 2017). Thus, in this study, it was ensured to employ the same conditions for cultivation of both the wild and the reference $F$. velutipes in terms of variables such as humidity, temperature, substrate, and other controlled environmental parameters. In addition, since post-harvesting conditions may affect the protein content (Lau et al. 2012), all the harvested sporomes were stored at $-80^{\circ} \mathrm{C}$ until use.

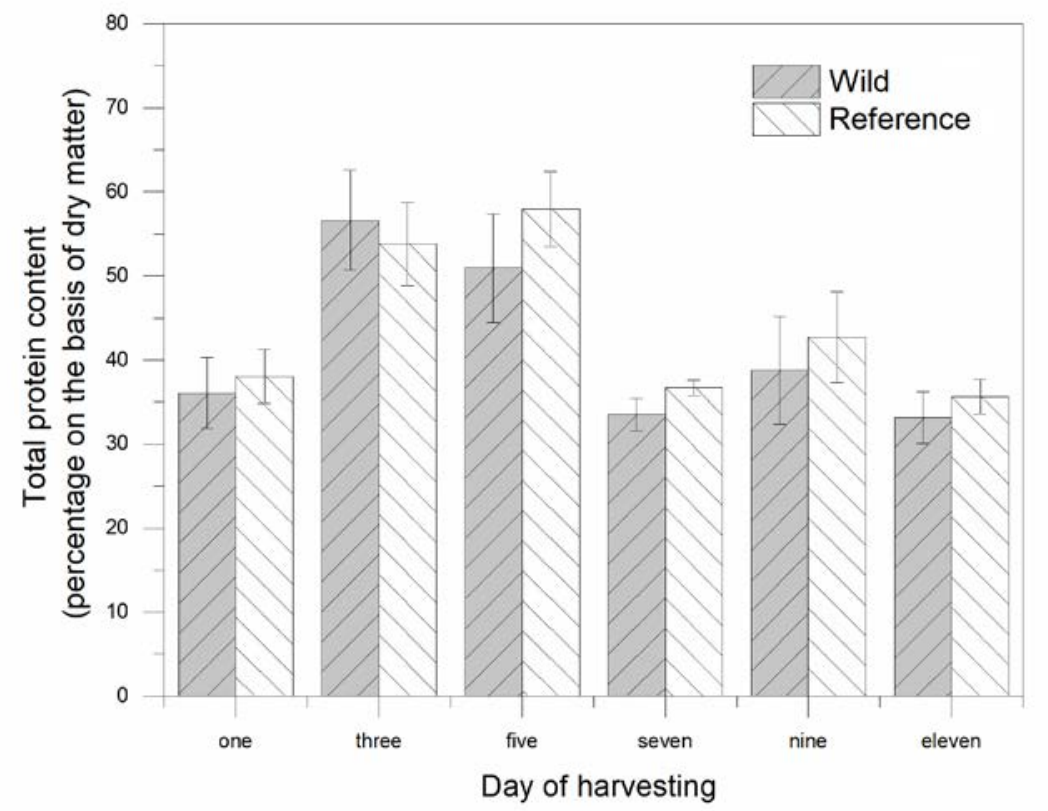

Fig. 1 - Total protein through PBS buffer extraction was obtained from sporomes of both wildgrowing and the reference $F$. velutipes. The sporomes were harvested in six maturation stages (i.e. primordia and three, five, seven, nine, and eleven days after appearance of primordia). Total protein was determined using extrapolation of the calibration curve of BSA and expressed as a percentage of dry matter. For each replication of each maturating stage, 30 sporomes were harvested and weighed followed by lyophilization. Then, $100 \mathrm{mg}$ of freeze-dried sporomes were used to extract and determine the total protein content. Data represent the means of three independent replications from which standard deviations were calculated.

The quantified data showed that total protein of the tested mushroom increased until the fifth day of harvesting after which a decline was noticed in the last days. These findings may immediately suggest optimum days for harvesting of this mushroom in terms of protein content. Further SDS-PAGE protein analysis confirmed changes in total protein content over the stages of harvesting. The confirmation was based on changes in intensities of the bands which might have direct relationships with concentration of proteins. On the other hand, the yield performance was also determined at each stage of harvesting. While the number of harvested sporomes was constantly 30 for each stage, fresh sporomes harvested at different stages showed different yield performance, including 2, 6, 15, 20, 27, and $33 \mathrm{~g}$ for primordial and mushrooms harvested at the 
third day, fifth day, seventh day, ninth day, and eleventh day, respectively. Thus, the optimum day for harvesting Enoki mushrooms in terms of protein contents (i.e. the fifth day) might not be necessarily the best time for harvesting high yielding mushrooms. Some other studies also suggested an early harvesting day as the optimum time for harvesting the wild mushrooms of highest protein content, which may confirm our findings in this study (Castronuovo et al. 2019). These findings also provide insights into the relationship between changes in protein content and changes in the use of $\mathrm{N}$ by the fungus.
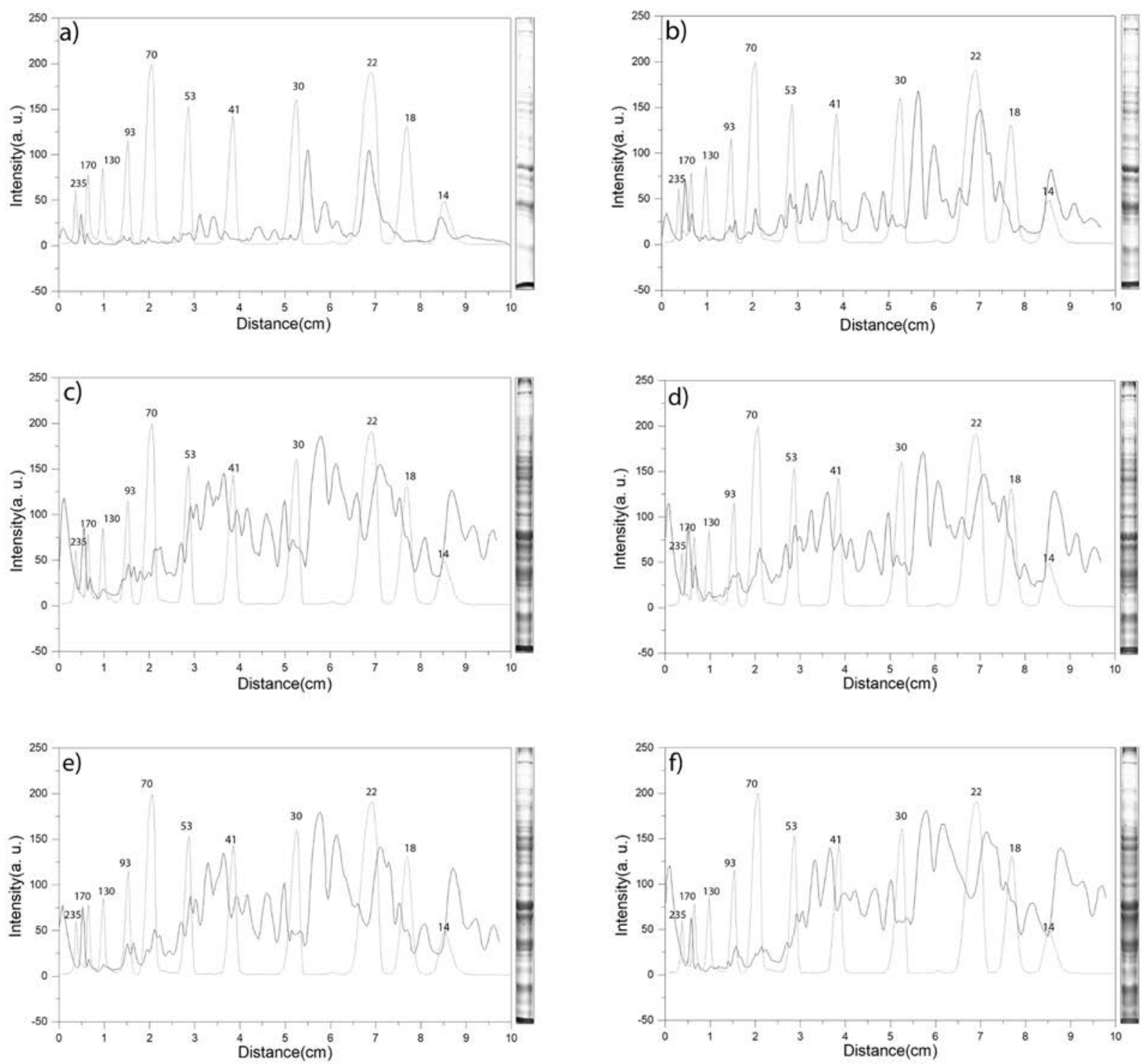

Fig. 2 - The SDS-PAGE electropherograms of total proteins were constructed for each stage of the wild F. velutipes, including primordia (a) and sporomes harvested in three days (b), five days (c), seven days (d), nine days (e), and eleven days (f) after appearance of primordia. For each replication of each maturating stage, 30 sporomes were harvested and weighed followed by lyophilization. Then, $100 \mathrm{mg}$ of freeze-dried sporomes were used to extract and determine the total protein content. In electrophoresis, $10 \mu \mathrm{L}$ (at a concentration of $10 \mathrm{ppm}$ ) of each protein sample was loaded into the gel. The image of protein bands observed in SDS-PAGE were converted to signals using GelAnalyzer software followed by PlotDigitizer. The background was normalized with advanced imageJ software using rolling ball algorithm (optimum radius, 50). Dash lines represent the protein ladder and molecular weight values $(\mathrm{kDa})$, while lines represent the Enoki mushroom samples. The intensities of the signals in each stage of harvesting (a to f) confirmed data obtained from crude protein of that stage (depicted in Fig. 1) 


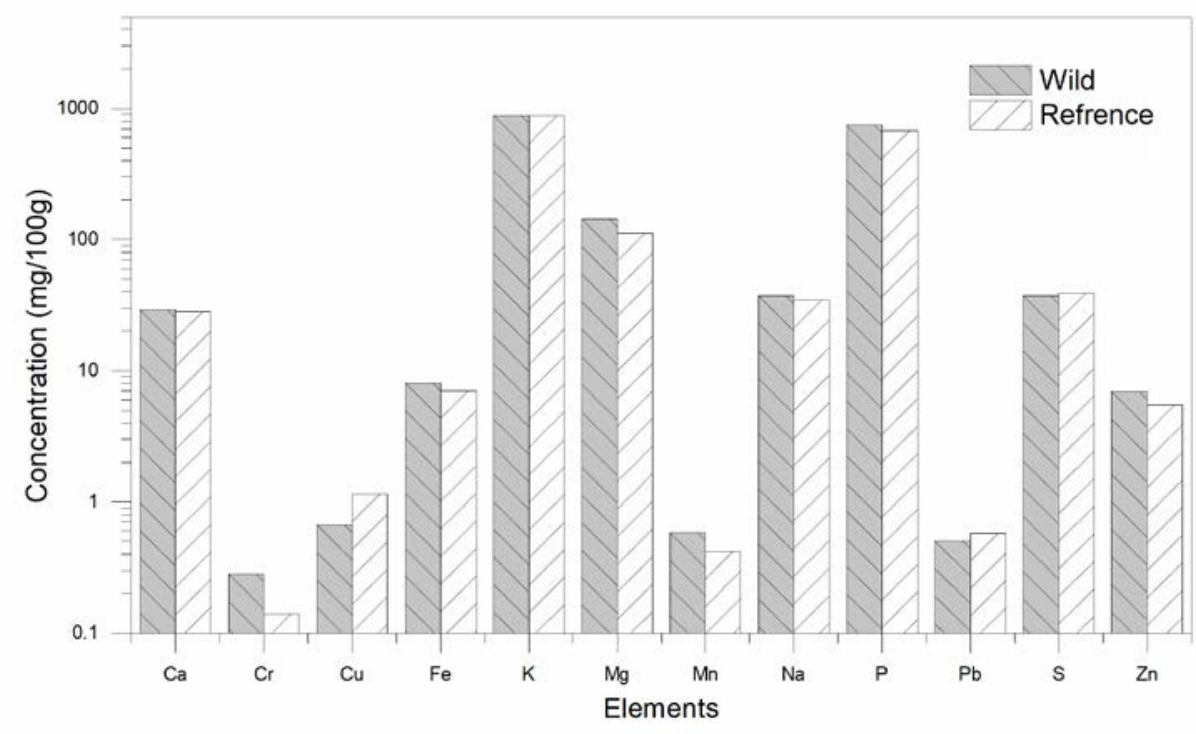

Fig. 3 - Nutritional elements obtained by ICP-UV/VIS in both wild and the reference strains of Enoki mushrooms (of dry weight). The $\mathrm{Y}$-axis is presented in the logarithmic scale. Co, $\mathrm{Ag}, \mathrm{Li}, \mathrm{Ni}$, and Se were below detection limit and are not presented in the graph.

The $\mathrm{N}$ content of the lignocellulosic substrate is the immediate source to be consumed during vegetative growth of mycelia. As the sporomes develop and grow up, the fungus continues to store $\mathrm{N}$ to form proteins until the middle stages of harvesting (Al-Obaidi 2016, Hsu et al. 2002). Then, as the $\mathrm{N}$ in substrate becomes limited, the fungus utilizes its stored nitrogen source for cell wall formation and weight increase (Rahmad et al. 2014), leading to a decline in total protein content of sporomes.

Changes in protein molecular mass during sporome formation might also have biological implications. In primordia and early stages of sporome maturation, proteins were found to be mostly of 25-32 kDa. These proteins normally represent the ribosome inactivating proteins, known to possess antifungal, antiviral, immunomodulatory and antitumor/anti-proliferative activities (Erjavec et al. 2012, Ng 2004). In the mature sporomes proteins with higher molecular weight were determined which are assumed to be up-regulated during the sporome formation and maturation (Rahmad et al. 2014). Pervious researches have showed that high molecular weight proteins belong to oxidoreductases enzymes (such as tyrosinase (42-55 kDa) and pyranose 2-oxidase (61-70 kDa) which play important roles in both aerobic and anaerobic metabolisms of mushrooms (Ng 2004). Consistent with this assumption, high molecular weight proteins of the tested $F$. velutipes in this study could have been present in the mature sporomes. However, proteins of Enoki mushroom (like any other mushroom) may be depolymerized during gastrointestinal digestion to very small peptides, making it essential to differentiate between nutritional and biomedical applications of proteins. Accordingly, proteins produced in any stage of fructification of wild Enoki may be directly used for biological activity, while the effectiveness of proteins for human nutrition depends on their composition of amino acids.

All the elements observed in the reference $F$. velutipes were also present in the wild strain without any significant difference. High concentrations of $\mathrm{K}, \mathrm{Ca}$ and $\mathrm{Mg}$ along with low amounts of $\mathrm{Na}$ present in the tested mushrooms would make them reliable sources of nutrition for preventing hypertension, neuromuscular irritability, osteoporosis, type 2 diabetes, and Alzheimer (Larsson \& Wolk 2007, Mallikarjuna et al. 2013, Moyer et al. 2013, Ozawa et al. 2012). In addition, functional foods such as mushrooms containing high amounts of Ca and protein likely possess high concentrations of P (Takeda et al. 2012). This fact may be confirmed in mushrooms by their ability to accumulate P in their sporomes (Kalač 2009) which make them natural remedies for patients with symptoms of low P (such as joint or bone pain, loss of appetite, irritability or 
anxiety and fatigue). It is noteworthy that the concentrations of the elements found in F. velutipes in this study are comparable to some other fungi species such as Pleurotus giganteus (Phan et al. 2019). These findings may suggest the potential value of the newly cultivated wild Iranian Enoki to be considered as a nutritious food. Similarly, it has been shown that Iranian wild genotypes have significant genetic differences with commercial cultivars which cause in resistance of the sporomes against diseases, which resulted to obtain healthier products (Rokni et al. 2019)

The occurrence and distribution of different toxic components in wild mushrooms are mycological problems with environmental and toxicological impacts (Mallikarjuna et al. 2013). In the present work, heavy metals such as $\mathrm{Cu}, \mathrm{Fe}, \mathrm{Zn}$ and $\mathrm{Mn}$ were at levels lower than the provisional maximum tolerable intake which is 2.2, 28-30, 15.5 and $5.5 \mathrm{mg} /$ day, respectively (Mallikarjuna et al. 2013). According to the established provisional tolerable weekly intake of heavy metals by FAO/WHO (Kalač 2010), it can be estimated that a weekly intake of $1000 \mathrm{~g}$ of fresh wild Enoki mushrooms (having dry matter content of $100 \mathrm{~g}$ ) for an adult with $70 \mathrm{~kg}$ bodyweight would be permissible. Thus, our findings would confirm that wild Enoki mushrooms cultivated in the substrate formulated in this study may be considered as a non-toxic food source in terms of heavy metals. It should be noted that substrate composition of a mushroom also plays a key role in quantity and quality of elements found in the sporomes, in addition to the individual difference in metals uptake among mushroom species. Thus, the use of unpolluted substrates for adaptation of wild mushrooms would lead to low accumulation of the detrimental elements.

\section{Conclusion}

This study might be considered as the first step towards recognition of an Iranian wild Enoki mushroom as a safe, non-toxic functional food, adapted to cultivation in lignocellulosic substrate composed of $40 \%$ wheat straw $+40 \%$ sawdust $+18 \%$ wheat bran $+1 \%$ lime $+1 \%$ gypsum. This study may also suggest that the best time for consumption of the wild Enoki as a culinary mushroom appears to be around 3-5 days after appearance of primordia, where sporomes produce high amounts of protein with a various range of high and low molecular weights. Therefore, the findings of this study may strongly encourage further attempts in order to gain deep insight into proteome of wild $F$. velutipes and its amino acid composition of proteins during different developmental stages.

\section{Acknowledgements}

This work was financed by Academic Center for Education, Culture and Research (ACECR), Iran (code number: 6003) granted to S-H Rezaeian.

\section{References}

Al-Obaidi JR. 2016 - Proteomics of edible mushrooms: A mini-review. Electrophoresis 37, 12571263.

Arana-Gabriel Y, Burrola-Aguilar C, Garibay-Orijel R, Matías-Ferrer N et al. 2018- Genetic characterization, evaluation of growth and production of biomass of strains from wild edible mushrooms of Lyophyllum of Central Mexico. Brazilian Journal of Microbiology 49, 632640.

Bradford MM. 1976 - A rapid and sensitive method for the quantitation of microgram quantities of protein utilizing the principle of protein-dye binding. Analytical Biochemistry 72, 248-254.

Castronuovo D, Mang SM, Becce A, Candido V et al. 2019 - Morphological and productivity comparison between commercial and wild isolates of Pleurotus eryngii (DC: Fr.) Quél. Italian Journal of Agronomy 14, 170-175.

Chen L, Zhang B-B, Cheung PCK. 2012 - Comparative proteomic analysis of mushroom cell wall proteins among the different developmental stages of Pleurotus tuber-regium. Journal of Agricultural \& Food Chemistry 60, 6173-6182. 
Debnath S, Debnath B, Das P, Saha A-K. 2019 - Review on an ethnomedicinal practices of wild mushrooms by the local tribes of India. Journal of Applied Pharmaceutical Science, 9, 144156.

Erjavec J, Kos J, Ravnikar M, Dreo T, Sabotič J. 2012 - Proteins of higher fungi - from forest to application. Trends in Biotechnololgy 30, 259-273.

Herawati E, Arung ET, Amirta R. 2016 - Domestication and nutrient analysis of Schizopyllum commune, alternative natural food sources in east Kalimantan. Agriculture and Agricultural Science Procedia 9, 291-296.

Hoa HT, Wang C-L, Wang C-H. 2015 - The effects of different substrates on the growth, yield, and nutritional composition of two oyster mushrooms (Pleurotus ostreatus and Pleurotus cystidiosus). Mycobiology 43, 423-434.

Hsu T-H, Shiao L-H, Hsieh C, Chang D-M. 2002 - A comparison of the chemical composition and bioactive ingredients of the Chinese medicinal mushroom DongChongXiaCao, its counterfeit and mimic, and fermented mycelium of Cordyceps sinensis. Food Chemistry 78, 463-469.

Jaworska G, Pogoń K, Skrzypczak A, Bernaś E. 2015 - Composition and antioxidant properties of wild mushrooms Boletus edulis and Xerocomus badius prepared for consumption. Journal of Food Science \& Technology 52, 7944-7953.

Kalač P. 2009 - Chemical composition and nutritional value of European species of wild growing mushrooms: A review. Food Chemistry 113, 9-16

Kalač P. 2010 - Trace element contents in European species of wild growing edible mushrooms: A review for the period 2000-2009. Food Chemistry 122, 2-15.

Larsson SC, Wolk A. 2007 - Magnesium intake and risk of type 2 diabetes: a meta-analysis. Journal of Internal Medicine 262, 208-214.

Lau C-C, Abdullah N, Shuib AS, Aminudin N. 2012 - Proteomic analysis of antihypertensive proteins in edible mushrooms. Journal of Agricultural \& Food Chemistry 60, 12341-12348.

Li H, Zhang Z, Li M, Li X, Sun Z. 2017 - Yield, size, nutritional value, and antioxidant activity of oyster mushrooms grown on perilla stalks. Saudi Journal of Biological Sciences 24, 347-354.

Li S, Wang A, Liu L, Tian G et al. 2018 - Evaluation of nutritional values of shiitake mushroom (Lentinus edodes) stipes. Journal of Food Measurement \& Characterization 12, 2012-2019.

Lindequist U, Niedermeyer TH, Jülich WD. 2005 - The pharmacological potential of mushrooms. Journal of Evidence-Based Integrative Medicine 2, 285-299.

Liu W, Huang Z, Li P, Xia J, Chen B. 2012 - Formation of triacylglycerol in Nitzschia closterium f. minutissima under nitrogen limitation and possible physiological and biochemical mechanisms. Journal of Experimental Marine Biology \& Ecology 418-419, 24-29

Luangharn T, Karunarathna SC, Khan S, Xu JC et al. 2017 - Antibacterial activity, optimal culture conditions and cultivation of the medicinal Ganoderma australe, new to Thailand. Mycosphere 8, 1108-1123.

Mallikarjuna SE, Ranjini A, Haware DJ, Vijayalakshmi MR et al. 2013 - Mineral composition of four edible mushrooms. Journal of Chemistry 2013: Article ID 805284.

Miles PG, Chang S-T. 2004 - Mushrooms: cultivation, nutritional value, medicinal effect, and environmental impact. CRC press.

Moyer VA, on behalf of the USPSTF. 2013 - Vitamin d and calcium supplementation to prevent fractures in adults: U.s. preventive services task force recommendation statement. Annals of Internal Medicine 158, 691-696.

Mridu, Atri NS. 2017 - Nutritional and nutraceutical characterization of three wild edible mushrooms from Haryana, India. Mycosphere 8, 1035-1043.

Ng TB. 2004 - Peptides and proteins from fungi. Peptides 25, 1055-1073.

Nikitina V, Loshchinina E, Vetchinkina E. 2017 - Lectins from mycelia of basidiomycetes. International Journal of Molecular Sciences 18, 1334.

Ozawa M, Ninomiya T, Ohara T, Hirakawa Y et al. 2012 - Self-reported dietary intake of potassium, calcium, and magnesium and risk of dementia in the Japanese: the Hisayama study. Journal of the American Geriatrics Society, 60, 1515-1520. 
Phan CW, Wang JK, Tan EYY, Tan YS et al. 2019 -Giant oyster mushroom, Pleurotus giganteus (Agaricomycetes): Current status of the cultivation methods, chemical composition, biological, and health-promoting properties. Food Reviews International 35, 324-341.

Quarcoo A, Adotey G, Gordon A. 2014 - Detection and quantification of trace elements (Chromium, Vanadium, Selenium) in some Ghanaian mushrooms using atomic absorption spectrometry. Current Research in Environmental \& Applied Mycology 4, 142-148.

Rahmad N, Al-Obaidi JR, Rashid NMN, Zean NB et al. 2014 - Comparative proteomic analysis of different developmental stages of the edible mushroom Termitomyces heimii. Biological Research 47, 30.

Rezaeian S, Pourianfar HR. 2017 - A comparative study on bioconversion of different agro wastes by wild and cultivated strains of Flammulina velutipes. Waste \& Biomass Valorization 8, 2631-2642.

Rokni N, Sadati SAA, Safaie N, Ebrahimi MA, Samimifar M. 2019 - Assessment of genetic relatedness among commercial and wild strains of Agaricus bisporus using repetitive extragenic palindromic sequences and polymerase chain reaction. Mycoscience 60, 293-297

Royse DJ, Baars J, Tan Q. 2017 - Current overview of mushroom production in the world. In: Cunha Zied D, Pardo-Giménez A (eds). Edible and Medicinal Mushrooms: Technology and Applications, 1st Ed. Wiley-Blackwell, Chapter 2.

Salmones D, Gaitan-Hernandez R, Mata G. 2018 - Cultivation of Mexican wild strains of Agaricus bisporus, the button mushroom, under different growth conditions in vitro and determination of their productivity. Biotechnologie, Agronomie, Société et Environnement 22, 45-53.

Shahtahmasebi SH, Pourianfar HR, Mahdizadeh V, Shahzadeh Fazeli SA et al. 2018 - A preliminary study on domestication of wild-growing medicinal mushrooms collected from Northern Iran. Current Research in Environmental \& Applied Mycology 8, 606-623.

Sharif S, Shahid M, Mushtaq M, Akram S, Rashid A. 2017 - Wild Mushrooms: A Potential Source of Nutritional and Antioxidant Attributes with Acceptable Toxicity. Preventive Nutrition \& Food Science, 22, 124-130.

Sharma SK, Atri NS. 2014 - Nutraceutical composition of wild species of genus Lentinus Fr. from Nothern India. Current Research in Environmental \& Applied Mycology 4, 11-32.

Sharma SK, Gautam N. 2015 - Chemical, bioactive, and antioxidant potential of twenty wild culinary mushroom species. BioMed Research International 2015, Article ID 346508.

Sulistiany H, Sudirman LI, Dharmaputra OS. 2016 - Production of fruiting body and antioxidant activity of wild Pleurotus. HAYATI Journal of Biosciences 23, 191-195.

Takeda E, Yamamoto H, Yamanaka-Okumura H, Taketani Y. 2012 - Dietary phosphorus in bone health and quality of life. Nutrition Reviews 70, 311-321.

Tan WC, Kuppusamy UR, Phan CW, Tan YS et al. 2015 - Ganoderma neo-japonicum Imazeki revisited: Domestication study and antioxidant properties of its basidiocarps and mycelia. Scientific Reports 5, 12515.

Tolera KD, Abera S. 2017 - Nutritional quality of Oyster Mushroom (Pleurotus ostreatus) as affected by osmotic pretreatments and drying methods. Food Science \& Nutrition 5, 989-996.

Tsai SY, Huang EW, Lin CP. 2017 - Compositional differences of the winter culinary-medicinal mushroom, Flammulina velutipes (Agaricomycetes), under three types of light conditions. International Journal of Medicinal Mushrooms 19, 267-276.

Wasser SP. 2014 - Medicinal mushroom science: Current perspectives, advances, evidences, and challenges. Biomedical Journal 35, 516-528.

Zarei M, Ahmadzadeh H, Goharshadi EK. 2015 - Embedded ceria nanoparticles in gel improve electrophoretic separation: a preliminary demonstration. Analyst 140, 4434-4444. 